\title{
Changes of biodiesel composition after electron beam irradiation
}

\author{
${\text { Paweł Grabowski }{ }^{1} \mathbb{C} \cdot \text { Dariusz Tomkielski }^{1} \cdot \text { Piotr Szajerski }^{2} \cdot \text { Hanna Gwardiak }}^{3,4}$
}

Received: 7 August 2018 / Published online: 3 December 2018

(c) The Author(s) 2018

\begin{abstract}
The study of the influence of external factors on FAME is increasingly being taken up with research topics. Under natural conditions, they are subject to aging. However, such studies are time-consuming, and it is difficult to find the right aging inhibitors. In the presented work an attempt was made to apply ionizing radiation to induce changes in FAME. On the basis of $\mathrm{GC}-\mathrm{MS}$ results, a reduction of mainly methyl esters containing $\mathrm{C}=\mathrm{C}$ double bonds can be observed. This indicates the occurrence of polymerization reactions induced by radicals arising during the absorption of ionizing radiation.
\end{abstract}

Keywords Biodiesel · e-beam irradiation $\cdot$ Gas chromatography-mass spectrometry $\cdot$ Saturated and unsaturated fatty acids

\section{Introduction}

According to the recommendations of Directive 2009/28/EC of the European Parliament and of the Council, until 2020 European Union member countries are obliged to achieve $10 \%$ share of biofuels in general use of petrol and diesel fuel in transport [1]. European Union requirements, combined with the awareness of finite natural resources and care for the environment, create need for research and development of new technologies for producing and improving biofuels.

Biofuels are gas or liquid products of biomass conversion, which is fundamental renewable energy source. Biomass is a general term for organic matter of living organisms. Substrates for obtaining biofuel are e.g.by-products generated by various kinds of plants, animals and in agriculture and forestry, industrial waste based on living organisms and crops cultivated to produce biofuel [2]. Generally, depending on raw material used, biofuels can be divided as following:

Paweł Grabowski

pawel.grabowski@pw.edu.pl

1 Institute of Chemistry, Faculty of Civil Engineering, Mechanics and Petrochemistry, Warsaw University of Technology, 17 Łukasiewicza St., 09-400 Płock, Poland

2 Department of Chemistry, Lodz University of Technology, 116 Zeromskiego St, 90-924 Lodz, Poland

3 Industrial Chemistry Research Institute, 8 Rydygiera St, 01-793 Warsaw, Poland

4 Present Address: Laboratory Masdiag, 27 Orzycka St, Warsaw, Poland
- first generation biofuels, obtained from edible crops,

- second generation biofuels, derived from uneatable resources,

- third generation biofuels, produced from algae [3].

Among biofuels that can be classified into each of above groups there is biodiesel. Biodiesel is the name for a variety of ester-based oxygenated fuels (and their blends with diesel fuel) for compression-ignition engines. Chemically, biodiesel consists of monoalkyl esters of long-chain fatty acids derived from renewable biolipids. Biodiesel [commonly known as FAME (Fatty Acid Methyl Esters)] is obtained in transesterification, which is the reaction of triglycerides with a short-chain alcohol, usually methanol or ethanol. Due to exchange of alkoxy groups fatty acid alkyl esters are formed, as well as glycerol as a by-product [4].

Biodiesel, apart from the obvious advantages (e.g. high flash point [4], high biodegradability [5] and low Particle Matter, Hydrocarbons and CO emissions [6]), has some drawbacks. The most important are oxidation stability problems and resulting negative effect on plastics and other engine elements [7]. Such disadvantages make the methods have been developed for improving the properties of biodiesel.

In the literature a lot of information can be found, concerning overview on the principles of radiation sources, the physics of energy absorption processes and the resulting radiation effects in organic materials and polymers where the reactions are often referred to as 'radiation chemistry', i.e. the chemical changes and reactions induced by the deposition of radiation 
energy [8-16]. Both ${ }^{60} \mathrm{Co}$ and e-beam sources can be used to induce changes in organic and inorganic materials, but e-beam in comparison with ${ }^{60} \mathrm{Co}$ source can be turned on and off. The radiation chemistry in organic materials (polymers and small molecules) depends on individual bond sensitivities and the chemical make-up of the material [8]. As is well known, radiation chemistry involves bond cleavage and bond formation (cross-linking, leading to larger molecules). Radiation induced reactions in organic materials involve a broad spectrum of processes, to name a few: detrimental and long-term polymer degradation, controlled curing of reactive resins initiated by e-beam, polymer modifications via radiation induced grafting reactions, surface modifications of biomaterials, radiation induced depolymerization which is positive when degradation and low molecular weights are required (i.e. recycling) and negative when uncontrollable materials degradation occurs, sterilization of materials, oxidation and rapid breakdown of organic contaminants (i.e. water purification), organic waste processing (scission and breakdown of molecules in sludge and solution), and many others [8-11].

In the industry the electron beam has a relatively more applicability compared to a gamma. In the case of electron beam energy can be fluently change, whereas gamma irradiation energy is dependent on applicable nuclide. Additionally, electron beam can be turn off at any moment. In case of gamma rays, emission energy of usually used nuclide ${ }^{60} \mathrm{Co}$ is 1.17-1.33 MeV (average 1.25 MeV), and emission energy of nuclide ${ }^{137} \mathrm{Cs}$ is $0.667 \mathrm{MeV}$ which is constant [13].

In the literature there is a lot of information concerning the preparation of microorganisms for synthesis of biofuels or sterilization materials for FAME production, such as algae [17-21]. During this processes structure of fatty acid chain can be changed, which will cause change in biodiesel properties.

The aim of this work is to study changes in composition of biodiesel irradiated by electron beam and to analyze them considering the influence of absorbed dose.

\section{Experimental}

The subject of this study was biodiesel derived from rapeseed (Rapeseed Methyl Esters, RME) produced in Poland, whose composition is presented in Table 2 as a non-irradiated sample. For the study were prepared 10 samples in glass vials, each vial containing $5 \mathrm{~mL}$ of biofuel. All chemicals were used as received from distributors without further purification.
Pulse radiolysis experiments were carried out with a high energy (6 MeV) 17 ns electron pulse generated from an ELU-6 linear electron accelerator. During the tests, the accelerator worked in a pulse mode with $20 \mathrm{~Hz}$ sweep. The current in the $4 \mu$ s pulse was $0.8 \mathrm{~A}$, at $20 \mathrm{~Hz}(50 \mathrm{~ms}$ period), and the impulse duration was $4 \mu \mathrm{s}$, which gives $49.996 \mathrm{~ms}$ without electricity. Each pulse consisted of 7500 micropulses (50 ps each).

The dose absorbed per pulse was determined on the basis of Fricke dosimeter ( $\mathrm{Fe}(\mathrm{II}) / \mathrm{Fe}(\mathrm{III}))$ adapted to work with high doses. The dose delivered per pulse was $680 \mathrm{~Gy}$. Details of pulse radiolysis system are given elsewhere [22, 23]. All experiments were carried out at room temperature and no aerator was used. The tests used glass ampoules according to DIN 58 377. All ampoules had the same thickness of the walls. Equipped with a ring to facilitate removal of the upper part of the ampoule. Calculated absorbed doses of all samples are presented in Table 1.

After irradiation, ultraviolet-visible (UV-Vis) and infrared (IR) spectra of the samples were recorded. In the study spectrophotometers PerkinElmer LAMBDA ${ }^{\mathrm{TM}} 750$ UV/Vis/ NIR and Mattson Genesis II FT-IR were used. Composition of samples was examined with the use of gas chromatograph Agilent 7890A with selective mass detector 5975C, according to PN-EN 14103 [24]. All of the research work for the irradiated samples were taken 2 weeks after irradiation. This time guarantees that the observed changes are a stationary state and there are no additional recombination changes in the obtained research samples.

\section{Results and discussion}

\section{UV-Vis spectroscopy}

Figure 1 presents UV-Vis spectra of all samples. The ' 0 kGy' label relates to nonirradiated reference sample.

As can be seen in Fig. 1, changes that are possible to interpret occur in chromophores absorbing in the range 250-300 nm (Fig. 2) and 370-530 nm (Fig. 3). From the points of view changes in RME composition other ranges can be neglected or there are no observable changes.

Radiation in the wavelength range from 200 to $800 \mathrm{~nm}$ is absorbed mainly by double bond systems exist in non-saturated fatty acid methyl esters. They can include from several to over a dozen bonds, depending on the compound [25].
Table 1 Doses of radiation absorbed by samples

\begin{tabular}{lllllllllll}
\hline Sample no. & 1 & 2 & 3 & 4 & 5 & 6 & 7 & 8 & 9 & 10 \\
\hline Absorbed dose (kGy) & 0.7 & 2.1 & 5.6 & 10.5 & 20.3 & 40.6 & 60.2 & 80.5 & 100.1 & 249.9 \\
\hline
\end{tabular}


Fig. 1 UV-Vis absorption of all tested samples
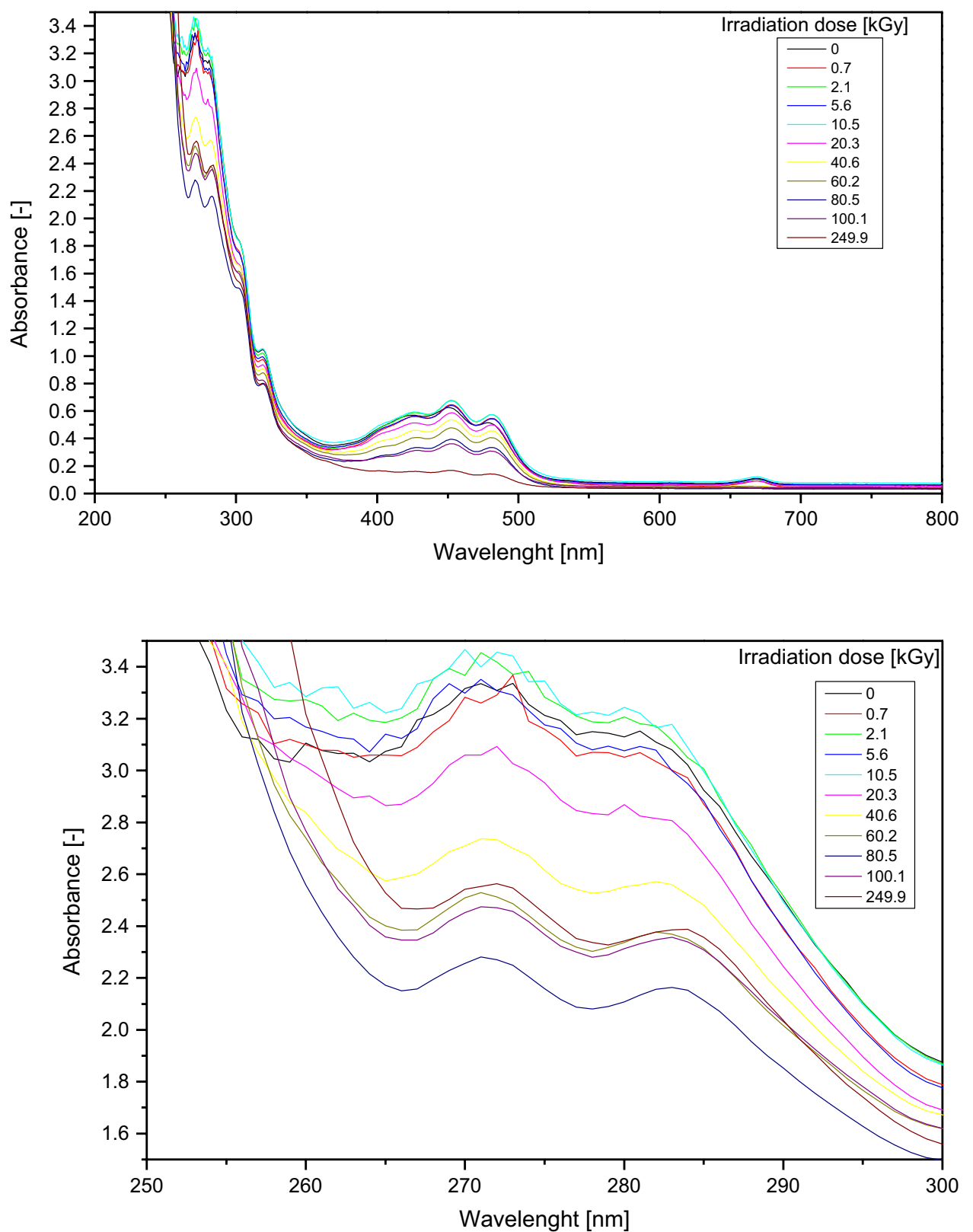

Fig. 2 UV-Vis absorption of all tested samples in the range 250-300 nm
As shown in Fig. 2, for the samples irradiated by the smallest doses (from 0 to $10.5 \mathrm{kGy}$ ) there is no significant change in absorption curves. At higher doses, as the dose increases to $40.61 \mathrm{kGy}$, the absorption decreases and then remains at approximately the same level. In this region can be observed two maxima distinguished-the first at about 270-272 $\mathrm{nm}$ and the second at about 283-284 nm. Absorption in this range occurs due to the transfer of electrons from bonding $\pi$ to antibonding $\pi^{*}$ orbitals in conjugated systems of several double bonds [25]. Unsaturated esters are probably responsible for the absorption, but it is also possible that pigments present in biodiesel are involved. Regardless of the actual explanation, it can be concluded that due to ionizing radiation a reduction in the number of double bond systems occurs.

In the range $370-530 \mathrm{~nm}$ presented on Fig. 3 there are two very clear absorption maxima at the wavelengths of $450 \mathrm{~nm}$ and $485 \mathrm{~nm}$. Conjugated with unsaturated bond systems exhibit absorption in visible light, e.g. $\beta$-carotene containing 11 double bonds has the absorption maximum at $445 \mathrm{~nm}$ [25]. Additionally, in this region can be observed absorption with maximum at $425 \mathrm{~nm}$.

In the presented visible range, there is clear correlation between the absorption intensity and the dose absorbed by samples. With the increase in dose, the absorbance decreases, i.e. the amount of carotenoids present in 
Fig. 3 UV-Vis absorption of all tested samples in the range $380-540 \mathrm{~nm}$

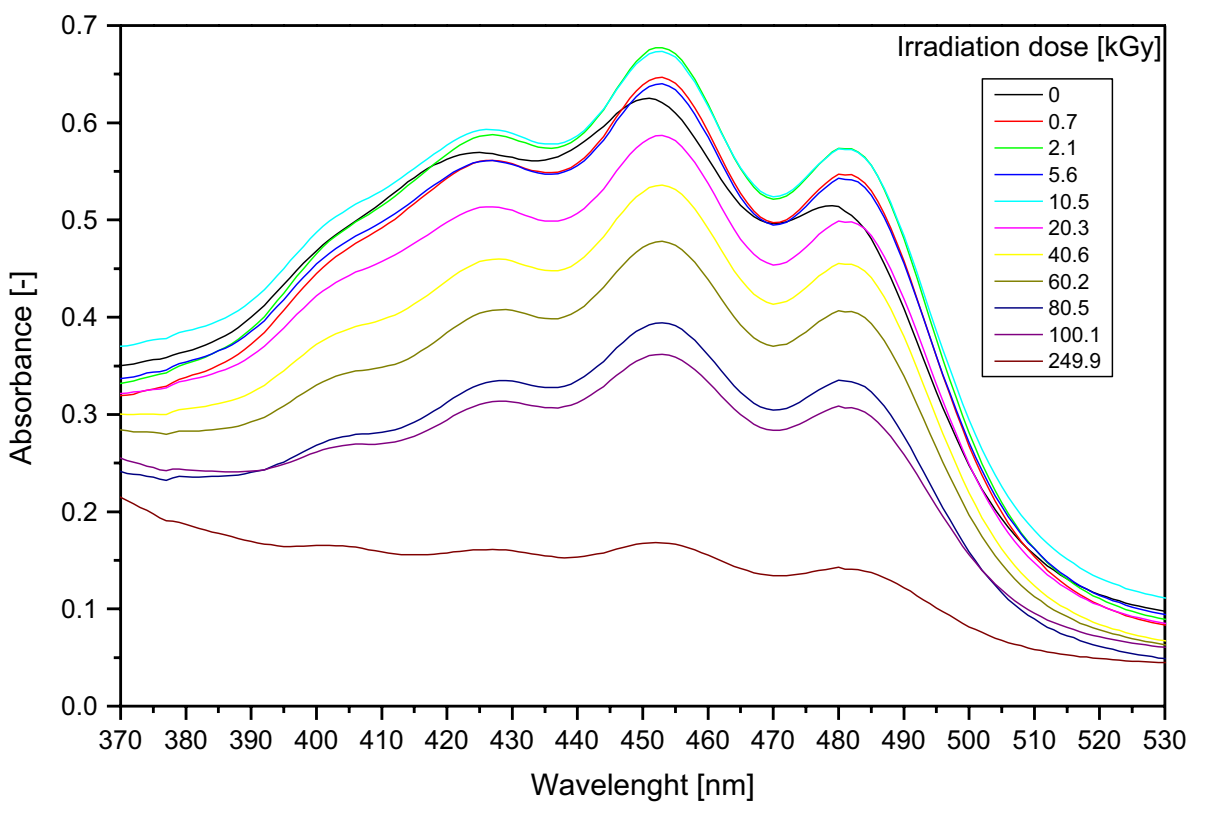

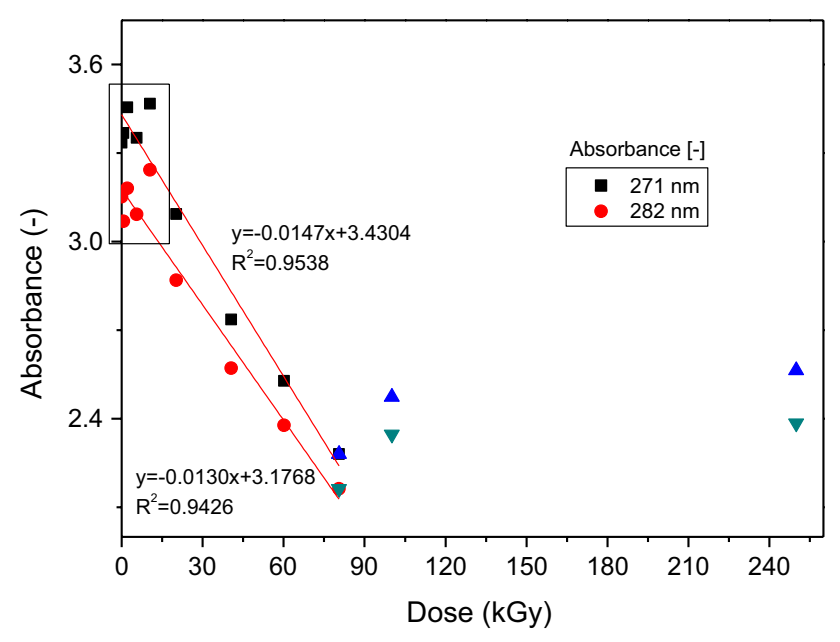

Fig. 4 Removal of carotenoids form biodiesel

biodiesel is reduced due to the destruction or transformation of unsaturated bond systems. Similar phenomena may occur in biodiesel itself. It is well known that carotenoids are good protectors of free radicals. Unfortunately, the removal of carotenoids from biodiesel adversely affects its properties. It disregards the possibility of free radicals resulting from the influence of external conditions such as light or elevated temperature.

Figure 4 shows how the dose affects the rate of removal of carotenoids.

According to this figure, it can be observed that up to a dose equal to $5.6 \mathrm{kGy}$ absorbance changes [and thus $c=f(A)$ ] concentrations are negligible. In this dose range, there is no change in absorbance relative to the non-irradiated sample.
The absorbance changes occur in the dose range from 5.6 to $60.2 \mathrm{kGy}$. Over $60.2 \mathrm{kGy}$ changes take on a statistical character. According to the presented dependence of the absorbance study on the occurrence of chromophore groups from carotenoids, this type of test can be used to determine the sterilization dose for biodiesel to eliminate biological life, but to preserve the full properties of the fuel.

\section{IR spectroscopy}

For a more comprehensive study, infrared spectroscopy was also used. IR spectra were normalised and presented in Fig. 5.

Tested RME samples consist of many esters of different fatty acids and residual amount of methanol after distillation process in refinery. Esters have long hydrocarbon chains (often containing unsaturated bonds) and functional ester groups -COO-, which causes overlapping of many bands. Therefore, the interpretation of the results is difficult.

In the range $1000-1600 \mathrm{~cm}^{-1}$ there are many bands corresponding to vibrations of $\mathrm{C}-\mathrm{H}$ and $\mathrm{C}-\mathrm{O}$ bonds, but they are hard to distinguish [25]. From the analytical point of view, these are vibrations corresponding to the bonds of higher fatty acids found in methyl esters, such as $\mathrm{C}-\mathrm{H}$, $\mathrm{C}-\mathrm{C}$, which occur in large quantities, which affects the inability to observe their changes.

Analysing the IR spectrum can be observed two ranges of interest, which include ranges of $1600-1800 \mathrm{~cm}^{-1}$ and $2780-3050 \mathrm{~cm}^{-1}$. In the first of them one can observe changes occurring in $\mathrm{C}=\mathrm{C}$ bonds and no changes in the case of $\mathrm{C}=\mathrm{O}$ bonds (Fig. 6a). Based on this data it can be 
Fig. 5 IR absorption of all tested samples in the range $800-4000 \mathrm{~cm}^{-1}$

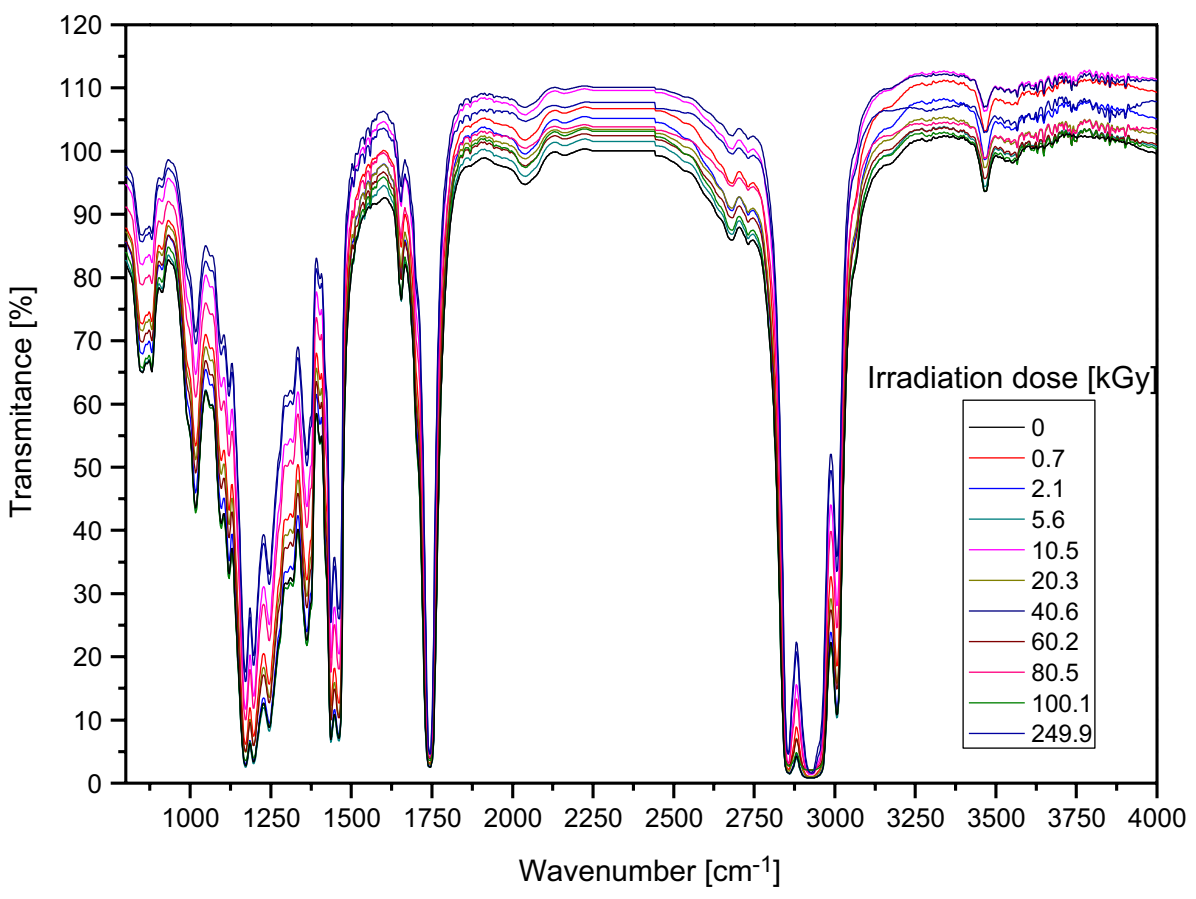

concluded that during the interaction of ionizing radiation with RME esters being a mixture of saturated and unsaturated esters, the ester bond-COO- does not change, whereas the $\mathrm{C}=\mathrm{C}$ unsaturated bond which may break or polymerize. Similar conclusions can be observed based on Fig. $6 \mathrm{~b}$, in the case of which no changes are observed in the case of $\mathrm{C}-\mathrm{H}$ bonds, while the change in the vibration severity occurs for the bond $=\mathrm{C}-\mathrm{H}$.

\section{Composition of samples (ester content)}

To accurately investigate changes in the composition of irradiated RME samples, gas chromatography was used. Measurements were made in accordance with the requirements of PN-EN 14103 [24]. Determined content of all esters present in biodiesel samples is shown in Table 2. The number accompanying ' $\mathrm{C}$ ' letter represents the total quantity of carbon atoms in the ester chain, an additional number indicates the amount of unsaturated bonds.

As can be observed based on Table 2, esters which concentrations decreases most are those which content in RME is the highest. The radiation reacts with the main constituents of biodiesel (the so-called matrix of the sample), that is why esters at low concentrations are not affected.

Electron radiation mostly influences on unsaturated methyl esters, such as methyl oleate (C18:1), methyl linoleate (C18:2), methyl linolenate (C18:3), methyl eicosanoate (C20:1) and saturated methyl palmitate (C16). Changes in concentration of these esters were presented in Fig. 7.
The most distinct difference in esters content was observed for methyl linoleate and methyl linolenate. For this samples the largest changes were observed between the nonirradiated sample and sample after radiation dose equalled $0.7 \mathrm{kGy}$. This change was observed up to $10.3 \mathrm{kGy}$. Further changes are not so significant considering the rate of increase in dose. Ester content and radiation dose are very well linearly correlated (R2 higher than 0.9 ) for the methyl ester acid C16, C18:1 and C20:1. For these esters up to $10.3 \mathrm{kGy}$ decrease concertation in correlation with radiation dose. It can be caused by polymerization unsaturated esters or degradation reaction of hydrocarbons chains what was observed on the basis IR results too.

The changes in the total concentration of esters were presented in Fig. 8 confirm the facts that up to $10 \mathrm{kGy}$ they are the most important changes in the composition of the samples. In the range from 0 to $10 \mathrm{kGy}$ changes are nearly linear with a coefficient $R^{2}$ equal to 0.8195 . At these doses the total concentration of the methyl esters of biodiesel decreases almost twice. In the doses range studied, the total concentration of methyl esters in biodiesel is decreasing from $96.89 \%$ for non-irradiated biodiesel to $37.55 \%$ for a radiation dose equal to $239.8 \mathrm{kGy}$. After exceeding the dose of $10 \mathrm{kGy}$ the changes are less intense, which suggests reducing the intensification of the polymerization reaction. After exceeding this dose, it is most likely that they start the degradation reaction of the resulting polymers as indicated by the lack of clear changes in the concentrations of esters also containing unsaturated bonds. 
Fig. 6 IR absorption of all tested samples $\mathbf{a}$ in the range $1600-1800 \mathrm{~cm}^{-1} \mathbf{b}$ in the range $2780-3050 \mathrm{~cm}^{-1}$
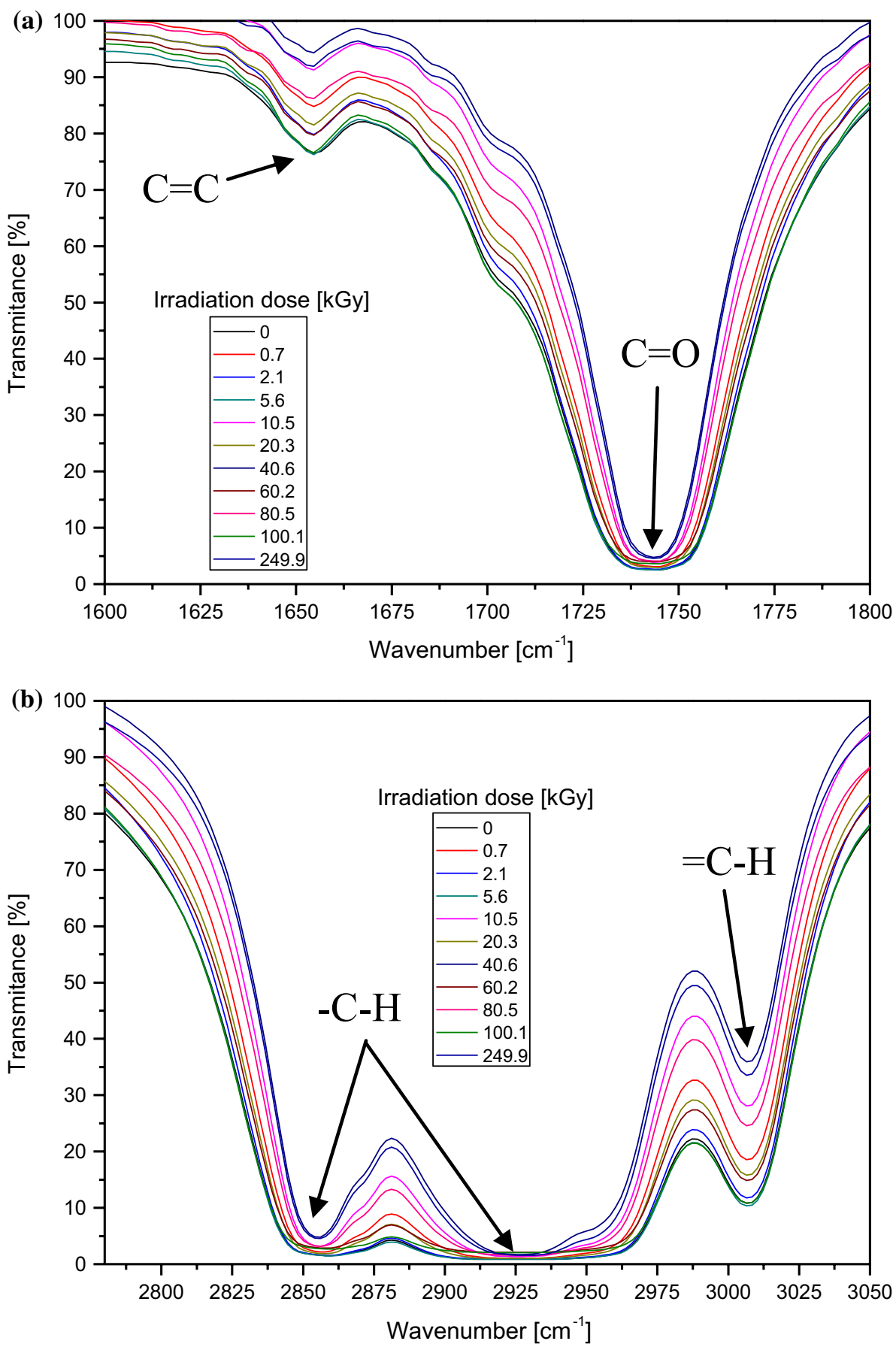

The presented studies show that small doses of ionizing radiation adversely affect the composition of RME. For a dose of $0.7 \mathrm{kGy}$, the concentration is reduced to $73.06 \mathrm{kGy}$, which according to the PN-EN 14214 [26] standard, makes it impossible to use this biodiesel as a diesel fuel.

\section{Dendrogram analysis}

Banding patterns generated for the data from analysis described in this article were used for cluster analysis and the creation of a dendrogram (Fig. 9). The dendrogram was performed using the TANAGRA software package [27]. The dendrogram was created using unweighted pair groupings of a similarity coefficient $\left(S_{\mathrm{AB}}\right)$ matrix, and consistently resulted in the groupings shown in Fig. 9. On the basis of this analysis the samples were divided into two clusters. Each group corresponds to different changes in sample composition. The first group is associated with low radiation doses that directly connect to the nonirradiated sample. In this group of samples reduced the concentration of the 
Table 2 Ester content in all tested RME samples

\begin{tabular}{|c|c|c|c|c|c|c|c|c|c|c|c|}
\hline & \multicolumn{11}{|c|}{ Radiation dose (kGy) } \\
\hline & 0.0 & 0.7 & 2.0 & 5.5 & 10.3 & 20.1 & 40.0 & 59.0 & 77.2 & 97.9 & 239.8 \\
\hline \multicolumn{12}{|c|}{ Content of particular methyl esters (wt\%) } \\
\hline $\mathrm{C} 14: 0^{*}$ & 0.13 & 0.12 & 0.13 & 0.12 & 0.12 & 0.12 & 0.11 & 0.12 & 0.12 & 0.12 & 0.11 \\
\hline $\mathrm{C} 16: 0$ & 4.84 & 4.63 & 4.58 & 4.45 & 4.24 & 4.20 & 4.15 & 4.24 & 4.22 & 4.21 & 4.09 \\
\hline C16:1 & 0.65 & 0.57 & 0.57 & 0.54 & 0.38 & 0.37 & 0.36 & 0.40 & 0.41 & 0.39 & 0.39 \\
\hline C18:0 & 1.77 & 1.69 & 1.68 & 1.66 & 1.57 & 1.56 & 1.54 & 1.58 & 1.57 & 1.56 & 1.53 \\
\hline C18:1 & 59.55 & 53.35 & 52.85 & 50.44 & 34.57 & 32.94 & 32.16 & 36.06 & 37.05 & 35.38 & 29.15 \\
\hline C18:2 & 18.70 & 8.05 & 7.79 & 5.66 & 0.15 & 0.10 & 0.09 & 0.23 & 0.31 & 0.20 & 0.04 \\
\hline C18:3 & 8.22 & 1.69 & 1.61 & 0.93 & 0.00 & 0.00 & 0.00 & 0.00 & 0.00 & 0.00 & 0.09 \\
\hline C20:0 & 0.54 & 0.52 & 0.51 & 0.51 & 0.47 & 0.47 & 0.46 & 0.47 & 0.47 & 0.47 & 0.45 \\
\hline C20:1 & 1.27 & 1.25 & 1.15 & 1.10 & 0.77 & 0.74 & 0.72 & 0.80 & 0.82 & 0.79 & 0.66 \\
\hline $\mathrm{C} 22: 0$ & 0.28 & 0.24 & 0.24 & 0.37 & 0.29 & 0.29 & 0.28 & 0.29 & 0.28 & 0.29 & 0.28 \\
\hline C22:1 & 0.44 & 0.46 & 0.45 & 0.44 & 0.32 & 0.30 & 0.29 & 0.34 & 0.35 & 0.33 & 0.26 \\
\hline $\mathrm{C} 24: 0$ & 0.12 & 0.13 & 0.14 & 0.13 & 0.00 & 0.00 & 0.00 & 0.00 & 0.00 & 0.00 & 0.02 \\
\hline C24:1 & 0.12 & 0.13 & 0.13 & 0.13 & 0.11 & 0.10 & 0.10 & 0.11 & 0.10 & 0.11 & 0.10 \\
\hline $\begin{array}{c}\text { Total ester } \\
\text { content } \\
\text { (wt } \%)\end{array}$ & 96.89 & 73.06 & 72.07 & 66.80 & 43.30 & 41.49 & 40.56 & 44.95 & 45.99 & 44.15 & 37.55 \\
\hline
\end{tabular}

*C14:0, methyl mirystate; C16:0, methyl palmitate; C16:1, methyl palmitoleate; C18:0, methyl stearate; C18:1, methyl oleate; C18:2, methyl linoleate; C18:3, methyl linolenate; C20:0, methyl arachidate; C20:1, methyl eicosanoate; C22:0, methyl behenate; C22:1, methyl erucate; C24:0, methyl lignocerate; C24:1, methyl nervonate unsaturated methyl esters which indicates the course of the polymerization reaction of these esters initiated by radicals produced during radiolysis. The second group consists of samples that have absorbed high doses of radiation. A sample exposed to the highest radiation dose (>10 kGy) may be considered as a two-separate group. The first group contains samples irradiated with radiation doses of 10.3, 20.1, 10.0 and $239.8 \mathrm{kGy}$, while in the second group 59.0, 97.9 and $77.2 \mathrm{kGy}$. As results from this analysis, the sample irradiated with the highest radiation dose shows a greater similarity to the samples irradiated with the dose in the range of 10-40 kGy than 60-100 kGy. This indicates the statistical effect of high radiation doses on hydrocarbon chains in methyl esters of higher fatty acids. Cluster analysis confirms observations resulting from direct analysis of data obtained from UV-VIS and GC studies. These results confirm that polymerization reactions occur up to $10 \mathrm{kGy}$. Above this dose degradation reactions begin. The polymers formed in the first phase of irradiation are being degraded. This reaction path is indicated by the lack of further decrease in the concentration of methyl esters being components of RME.

Analysis using the dendrogram in the future could be used to quickly assess the radiation dose that has been applied to the tested biodiesel samples. Especially important is this information in the case of further use of biodiesel, as fuel for self-ignition engines, for which it must meet the parameters contained in the PN EN ISO 14214 standard.

\section{Conclusions}

Ionizing radiation initiates chemical reactions in the test samples of RME. The reactions were concern with decrease of $\mathrm{C}=\mathrm{C}$ bonds number, whereas $\mathrm{C}=\mathrm{O}$ bonds remain intact. This is caused the presence of esters containing one, two or three double bonds $\mathrm{C}=\mathrm{C}$. Analysis in ultraviolet-visible range indicates that electron beam mainly influences on unsaturated bonds in ester chains. However, the UV-Vis spectroscopy results may be affected by the presence of carotenoids in biodiesel (the range from 370 to $530 \mathrm{~nm}$ ). In the range from 260 to $300 \mathrm{~nm}$ was observed changes in double bound systems. As was shown on the basis of conducted research these systems changed due to increase of radiation dose. According to PN-EN ISO 14214 guidelines, the concentration of methyl esters in the RME used as a biofuel should be above $96.5 \%$. According to the research results, the application of the lowest $0.7 \mathrm{kGy}$ dose results in a significant reduction in the ester content and in not meeting the quoted norm. Based on GC-MS results, a reduction of mainly methyl esters containing $\mathrm{C}=\mathrm{C}$ double bonds can be observed. This indicates the occurrence of polymerization reactions induced by radicals arising during the absorption of ionizing radiation.

The most important problem in the operation of biodiesel is the rapid development of biological microflora, 

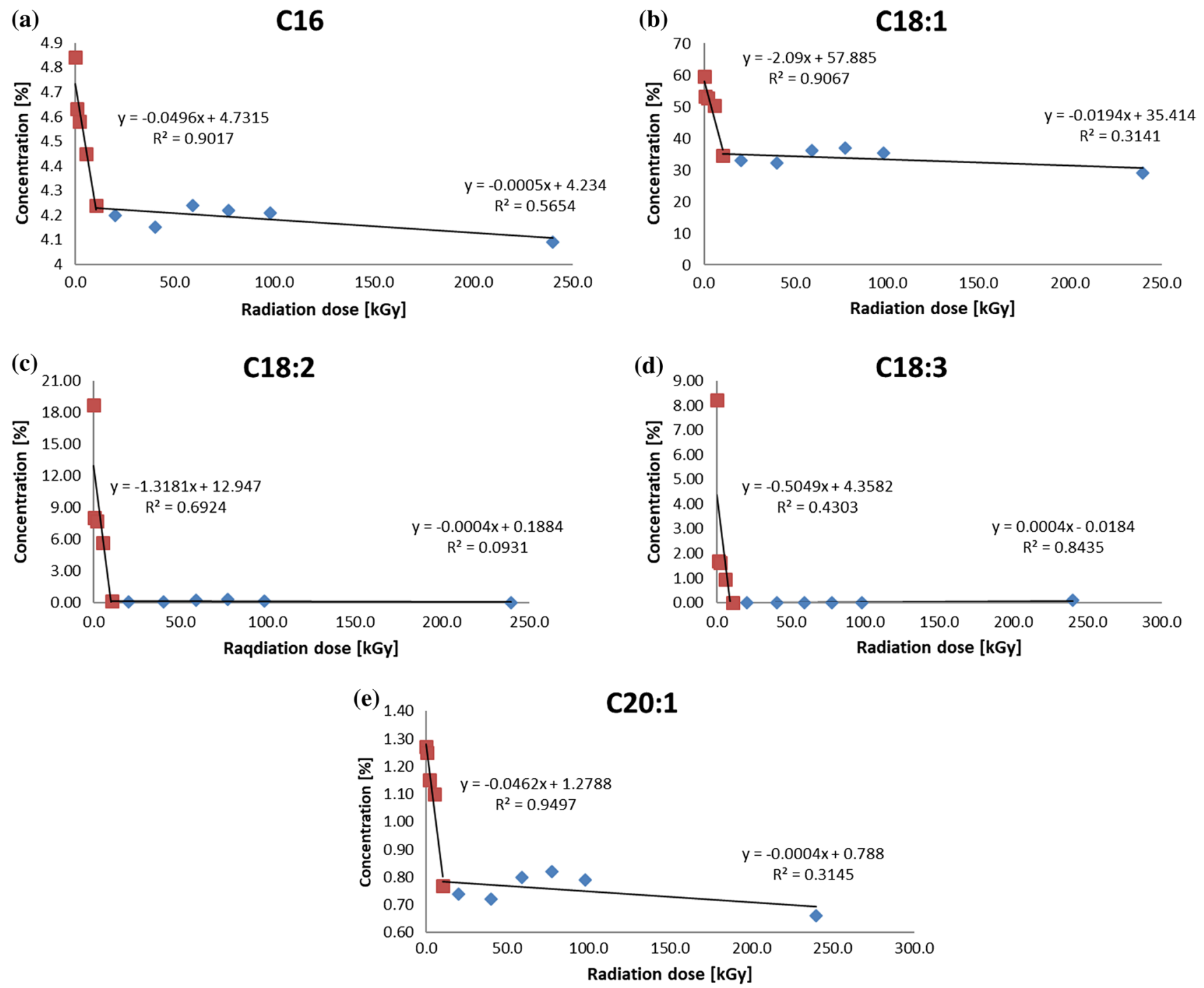

Fig. 7 Concentration change of methyl esters versus radiation dose: a C16:0-methyl palmitate, b C18:1-methyl oleate, c C18:2-methyl linoleate, d C18:3-methyl linolenate, e C20:1—methyl eicosanoate

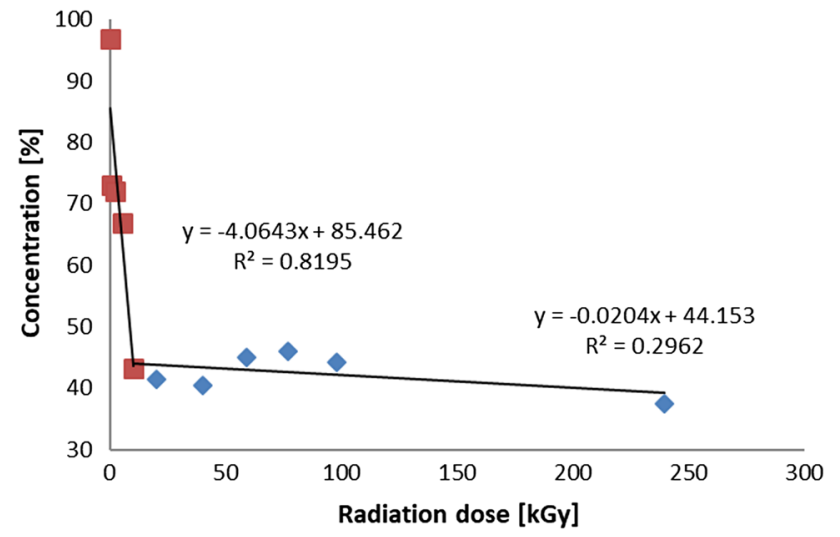

Fig. 8 Total ester concentration as a function radiation dose which significantly worsens its physicochemical properties. This work is a very important step in order to deal with unconventional methods of eliminating this problem already at the FAME production stage (in Central and Eastern Europe, mainly RME). The use of ionizing radiation can cause sterilization of the biofuel obtained and thus avoid the development of microbiological life in storage tanks. However, the use of this solution requires learning about the influence of radiation on the composition of biodiesel, as well as physicochemical parameters, which is the subject of future research by the authors of the work. 


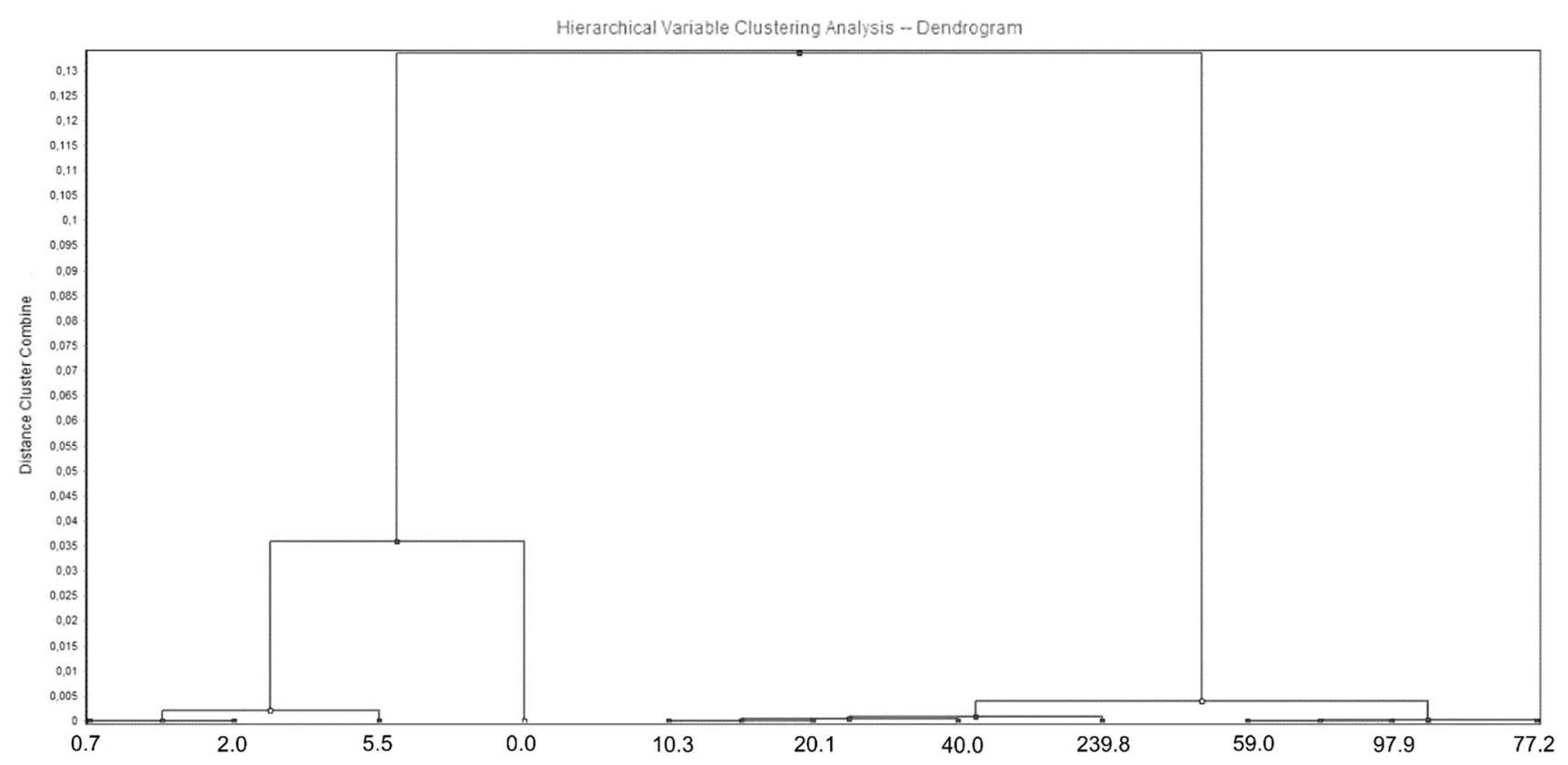

Fig. 9 Cluster analysis for UV-Vis and GC result

\section{Compliance with ethical standards}

Conflict of interest All authors declare that they have no conflict of interest.

Open Access This article is distributed under the terms of the Creative Commons Attribution 4.0 International License (http://creativeco mmons.org/licenses/by/4.0/), which permits unrestricted use, distribution, and reproduction in any medium, provided you give appropriate credit to the original author(s) and the source, provide a link to the Creative Commons license, and indicate if changes were made.

\section{References}

1. Directive 2009/28/EC of the European Parliament and of the Council on the promotion of the use of energy from renewable sources

2. Lee KO, Chung KH (2008) Method for producing biofuel using electron beam. US patent 20080313954 A1

3. Lee RA, Lavoie JM (2013) From first- to third-generation biofuels: challenges of producing a commodity from a biomass of increasing complexity. Anim Front 3:6-11

4. Demirbas A (2008) Biodiesel—a realistic fuel alternative for diesel engines. Springer, London

5. Blin J, Volle G, Girard P, Bridgwater T, Meier D (2007) Biodegradability of biomass pyrolisis oils: comparison to conventional petroleum fuels and alternative fuels in current use. Fuel 86:2679-2686

6. Wang WG, Lyons DW, Clark NN, Gautam M (2000) Emissions from nine heavy trucks fueled by diesel and biodiesel blend without engine modification. Environ Sci Technol 34:933-939

7. Pullen J, Saeed K (2012) An overview of biodiesel oxidation stability. Renew Sust Energ Rev 16:5924-5950
8. Leathers L, Celina M, Chianelli R, Thoma S, Gupta V (2007) Systems analysis and futuristic designs of advanced biofuel factory concepts, Sandia Report-SAND2007-6872

9. Clegg DW, Collyer AA (1991) Irradiation effects on polymers. Elsevier, New York

10. Clough RL (2001) High-energy radiation and polymers: a review of commercial processes and emerging applications. Nucl Instrum Methods Phys Res B 185:8-33

11. Clough RL, Shalaby SW (1991) Radiation effects on polymers. ACS Publications, Washington, DC

12. Clough RL, Shalaby SW (1996) Irradiation of polymers: fundamentals and technological applications. ACS Publications, Washington, DC

13. Dole M (1973) The radiation chemistry of macromolecules. Academic Press, New York

14. Kochetkov NK, Kudryashov LI, Chlenov MA (1979) Radiation chemistry of carbohydrates. Pergamon Press, Oxford

15. Schnabel W (2014) Polymers and electromagnetic radiationfundamentals and practical applications. Wiley-VCH, Weinheim

16. Woods RJ, Pikaev AK (1994) Applied radiation chemistry: radiation processing. Wiley, New York

17. Kroh J (1986) Selected issues of radiation chemistry. PWN, Warsaw (in Polish)

18. Driscoll MS, Stipanovic AJ, Cheng K, Barber VA, Manning M, Smith JL, Sundar S (2014) Ionizing radiation and a wood-based biorefinery. Radiat Phys Chem 94:217-220

19. Joe MH, Kim JY, Lim S, Kim DH, Bai S, Park H, Lee SG, Han SJ, Choi JI (2015) Microalgal lipid production using the hydrolysates of rice straw pretreated with gamma irradiation and alkali solution. Biotechnol Biofuels 8(125):1-9

20. Kovacs E, Keresztes A (2002) Effect of gamma and UV-B/C radiation on plant cells. Micron 33:199-210

21. Sundar S, Bergey NS, Salamanca-Cardona L, Stipanovic A, Driscoll M (2014) Electron beam pretreatment of switchgrass to enhance enzymatic hydrolysis to produce sugar for biofuels. Carbohydr Polym 100:195-201 
22. Karolczak S, Hodyr K, Łubis R, Kroh J (1986) Pulse radiolysis system based on ELU-6E LINAC. J Radioanal Nucl Chem 101(2):177-188

23. Czerwinska M, Sikora A, Szajerski P, Adamus J, Marcinek A, Gebiski J (2006) Mechanistic aspects of alloxan diabetogenic activity: a key role of keto-enol inversion of dialuric acid on ionization. J Phys Chem A 110:7272-7278

24. PN-EN 14103 Fat and oil derivatives-fatty acid methyl esters (FAME) — determination of ester and linolenic acid methyl ester contents
25. Kumar S (2006) Spectroscopy of organic compounds. National Science Digital Library at NISCAIR, New Delhi

26. PN-EN 14214 Liquid petroleum products—fatty acid methyl esters (FAME) for use in diesel engines and heating applications-requirements and test methods

27. Rakotomalala R (2005) TANAGRA: a free software for research and academic purposes. Proc EGC 2005 RNTI-E-3 2, pp 697-702 (in French) 